\title{
Evaluation and spatial aggregation of ecological water use in each region of the Yellow River Basin
}

\author{
Wang Huiliang ${ }^{1,2}$, Li Hui ${ }^{3}$, Di Danyang ${ }^{2}$, Yan Dengmin ${ }^{1 *}$ \\ ${ }^{1}$ Yellow River Engineering Consulting Co., Ltd., Zhengzhou 450003, China \\ ${ }^{2}$ School of Water Conservancy Engineering ZZU, Zhengzhou University, Zhengzhou 450001, China \\ ${ }^{3}$ School of Geographical Science and Tourism, Nanyang Normal University, Nanyang 473061, China
}

\begin{abstract}
Ecological water is the basic condition to maintain river health in a water-deficient basin. The evaluation and spatial distribution of ecological water are significance to the allocation of water resources under the concept of ecological civilization. In this paper, the connotation and composition of value of ecological water are defined from the perspective of ecosystem material circulation. Based on the emergy theory, the quantitative methods of different types of ecological water value are proposed. Combined with the spatial autocorrelation analysis method, the analysis method of spatial distribution and aggregation characteristics of watershed ecological water value is established. We took the Yellow River Basin as an example, and estimated and analysed its ecological water value and the spatial distribution characteristics according to the 9 regions of basin. The results showed that: In the Yellow River Basin, the single water value of the ecological water in the river channel is 17.45-24.36 yuan, the single water value of the sediment transport water is 2.42-7.28 yuan, and the single water value of the ecological water outside the river channel is 10.87-16.61 yuan. Ecological water value presents obvious difference in the space. Both outside and inside the river course, the high concentration areas of ecological water value are in the middle and lower reaches, while the low concentration areas are in the lower reaches, which indicates that we should consolidate the ecological water value in the middle and lower reaches and enhance the water value in the upper reaches. The research results have guiding significance for the allocation of ecological water in each province and region.
\end{abstract}

\section{Introduction}

Ecological water (EW) refers to the amount of water used in the process of natural ecological protection and artificial ecological construction in order to maintain the specific structure, ecological process and ecosystem service function of the ecosystem under a certain inflow condition [1]. Adequate water quantity and good water quality are the basis and guarantee to maintain the normal operation of the ecosystem [1]. To fully understand the ecological water value and its spatial distribution characteristics is of great guiding significance to the rational allocation of water resources.

The value of EW is the performance of ecological water use benefit. From the perspective of ecosystem, EW has the functions of regulating and storing flood, accumulating water resources, purifying environment, fixing carbon, providing habitat and maintaining biodiversity; In addition, EW should also have certain economic service function. In recent years, with the increase of urban water system research, some scholars have proposed that water ecosystem service function is based on water purification, habitat diversity as the core, and cultural service as the key [2]. The above studies all lay the foundation for the analysis of the connotation and composition of river ecological environmental benefits, but there is no definition of the connotation of the value of EW at present, especially for the muddy river with water shortage. The composition of the value of EW needs to be further studied. In terms of water value accounting, the main methods include shadow price method, cost analysis method, computable general equilibrium model method, fuzzy mathematical model accounting method, emergy analysis method, etc. [3]. Due to the different times and the subjective differences in research perspectives, methods and theoretical preferences of various researchers, all methods have certain limitations [4]. In recent years, emergy analysis method is introduced into water resources value evaluation, which can quantify different types and dimensions of input and output, and promote the water resources benefit evaluation. At the same time, the spatial balance of water resources allocation is a hot topic in recent years, and the main problem is that different regions have different water resources benefits due to different social economy [5]. Relevant researches mainly focus on the spatial distribution of water resources carrying capacity, water resources ecological footprint, water resources utilization efficiency, while the research on the

First author's e-mail address: wanghuiliang@zzu.edu.cn

*corresponding author: 18519500795@163.com 
spatial distribution of water resources value is relatively rare.

In view of the above problems, this paper combines emergy analysis method which can measure the value of ecological water use with spatial autocorrelation analysis method, and takes the Yellow River Basin as the research object to explore the spatial aggregation of the value of the EW.

\section{Methods and Materials}

\subsection{Ecological water value estimation method}

\subsubsection{Connotation and composition of ecological water value}

The energy flow process of the ecological environment subsystem of water resources is the process in which the energy of water resources acts on the seven ecological environments of rivers, wetlands, lakes, swamps, forests, grasslands and silts. The energy of water resources includes the energy contained in renewable environmental resources, such as chemical energy, potential energy, solar energy, wind energy and earth rotation energy, as well as the energy from economic and social labor and science and technology. This process embodies the functions of material transportation, water quality improvement, aquatic biological maintenance, evaporative heat dissipation, landscape appreciation, river and lake water replenishment, and urban water replenishment, and materializes the ecological and environmental value stream of water resources, and finally realizes the ecological and environmental value of water resources. Based on this concept, the ecological water value of the Yellow River basin can be divided into the ecological water value outside the river course (V-OUT), the ecological water value inside the river course (V-IN) and the sediment transport water value (V-SED). Among them, V-OUT includes dilution and purification value, landscape value and urban purification value, while V-IN includes protection value of biological germplasm resources, self-purification value of water body, regulation of climate value and nutrient cycling accumulation value.

\subsubsection{Emergy calculation of ecological water value}

The method of emergy analysis is used to calculate the ecological water value. The idea is to convert the energy input and value output of the ecological economic system of water resources into emergy uniformly, so as to realize the unified quantification of different dimensional values. The basic conversion formula is formula 1 .

$$
E M=\tau \times B
$$

Where: $E M$ is the emergy (sej); $\tau$ is the emergy conversion rate (sej / $\mathrm{J}$ or sej / $\mathrm{g}$ ); $B$ is the energy or mass of the substance ( $\mathrm{J}$ or $\mathrm{g})$.

Table 1 The emergy evaluation formula of various ecological water values*

\begin{tabular}{lll}
\hline Type & Name & Formula \\
\hline \multirow{2}{*}{ V-OUT } & dilution and purification & $E M_{A}=W_{t} \times \tau_{t}$. \\
& landscape value & $E M_{V}=L \times \eta \times \xi_{E} \times E D R$, \\
& urban purification value & $E M_{Q}=\left(2507.4-2.39 T_{t}\right) \times W_{l} \times \gamma_{z}$ \\
& protection value of germplasm & $E M_{G}=N \times R_{b} \times \tau_{g} \times \xi_{E}$. \\
& self-purification value of water body & $E M_{P}=f \times \xi_{E} \times \sum_{p=1}^{n} m_{p} \times \tau_{p}$. \\
V-IN & regulation of climate value & $E M_{R}=\left(2507.4-2.39 T_{t}\right) \times G \times \tau_{z}$. \\
& nutrient cycling accumulation value & $E M_{N}=G_{n} \times \tau_{n} \times \xi_{E}$. \\
V-SED & maintain river functions & $E M_{D}=\left(\Delta P_{E}+\Delta K_{E}\right) \times\left(\theta_{1}+\theta_{2}\right) \times \tau_{d}$, \\
\hline
\end{tabular}

$*$ The meaning of the parameters in the formula can be referred to references 3 and 4 .

The emergy/money ratio index can realize the conversion between emergy and money quantity, and the calculation formula is formula 2 .

$$
E D R=E M / G D P
$$

Where: EDR is emergy/currency ratio.

\subsection{Spatial distribution characteristics of ecological water value}

\subsubsection{Discrimination of spatial aggregation}

Spatial autocorrelation analysis is to analyze the correlation characteristics of the same variable among different objects observed in the space, which can be introduced into the study of spatial dimension of water value, and to analyze the spatial correlation characteristics of the same value variable among different regions of the basin. Global spatial autocorrelation analysis was used to determine whether the same value variable had spatial aggregation in the whole basin. The global spatial autocorrelation is represented by Moran index $\mathrm{I}$, and the calculation method is shown in Formula 3. 


$$
I=\frac{\sum_{i=1}^{n} \sum_{j=1}^{n} w_{i j}\left(x_{i}-\bar{x}\right)\left(x_{j}-\bar{x}\right)}{S^{2}\left(\sum_{i=1}^{n} \sum_{j=1}^{n} w_{i j}\right)}
$$

Where: $I$ is the Moran index, $x_{i}$ is the value of EW of a city $i$ in the river basin, $w_{i j}$ is the spatial weight matrix, $\bar{x}$ is the average value of the EW; $S^{2}$ is the variance of the value of EW.

\subsubsection{Spatial aggregation location and characteristics}

Local Indicators of Spatial Association(LISA) can directly express Spatial aggregation characteristics of regional water value variables by Moran scatter plot, and LISA cluster plot can display Spatial aggregation location. By drawing Moran scatter plot and Lisa cluster plot, the spatial relationship of water value variables in different regions of the basin can be characterized. The Moran scatter plot is divided into four quadrants, which represent high-value agglomeration areas, high value surrounded by low value area, low value surrounded by high value area and low value agglomeration area.

\section{3 study area and data collection}

Considering the consistency of regional space and the availability of data, this paper defines its research scope as 59 cities in the Yellow River Basin. The research's time period encompasses the year 2015. The water consumption data required for this study come from the "China Water Conservancy Statistical Yearbook 2016", "Water Resources Bulletin 2015 of the Yellow River
Basin", and municipalities "Water Resources Bulletin 2015". The data required for the quantification of emergy come from the "China Agricultural Statistical Yearbook 2016", the provincial "Statistical Yearbooks", and the "Statistical Yearbooks" of varies cities. The emergy/currency ratio comes from the literature.

\section{Results and discussion}

\subsection{Quantitative results and analysis of ecological water value in the Yellow River Basin}

The emergy evaluation calculation method was applied to quantify the ecological water value of the Yellow River Basin firstly. Then, according to the emergy quantification results and emergy currency conversion rate, the unilateral water value of ecological water was obtained, as shown in Table 2. It can be seen that the ecological water value of the Yellow River Basin shows the following characteristics: (1) On the whole, the single water value of the ecological water in the river channel is larger than that of the ecological water outside the river channel; (2) The unilateral water value in the middle and lower reaches is higher than that in the upper reaches, both for the ecological water outside the river and for the ecological water inside the river. The largest is in Shaanxi Province, and the lowest is in Sichuan Province. (3) As for the sediment transport value, the sediment transport value of Ningxia Hui Autonomous Region, Inner Mongolia Autonomous Region, Henan Province and Shandong Province is relatively high because of the small sediment content in the upper reaches of the river and the provinces (regions) in the middle and lower reaches assume the main sediment transport function.

Table2 The unilateral water value of ecological water (Yuan $/ \mathrm{m}^{3}$ )

\begin{tabular}{cccccccccc}
\hline Value & Qinghai & Sichuan & Gansu & Ningxia & Neimeng & Shaanxi & Shanxi & Henan & Shandong \\
\hline V-IN & 18.91 & 17.45 & 20.68 & 20.75 & 21.47 & 24.36 & 21.73 & 23.88 & 23.45 \\
V-OUT & 11.10 & 10.87 & 13.80 & 14.20 & 15.44 & 16.61 & 14.00 & 11.50 & 11.16 \\
V-SED & 3.71 & 2.42 & 4.07 & 6.25 & 6.56 & 5.24 & 4.27 & 6.82 & 7.28 \\
\hline
\end{tabular}

\subsection{Analysis on spatial aggregation characteristics of ecological water value in the Yellow River Basin}

According to the global spatial autocorrelation model, the global Moran index I of the single water value of ecological water use in the Yellow River Basin, the single water value of ecological water use in the river channel, the single water value of ecological water use in the river channel and the single water value of sediment transport water use are $0.558,0.418$ and 0.486 , respectively, as shown in Figure 1. The results indicate that there is a strong spatial positive correlation between the ecological water value outside the river channel and inside the river channel. 


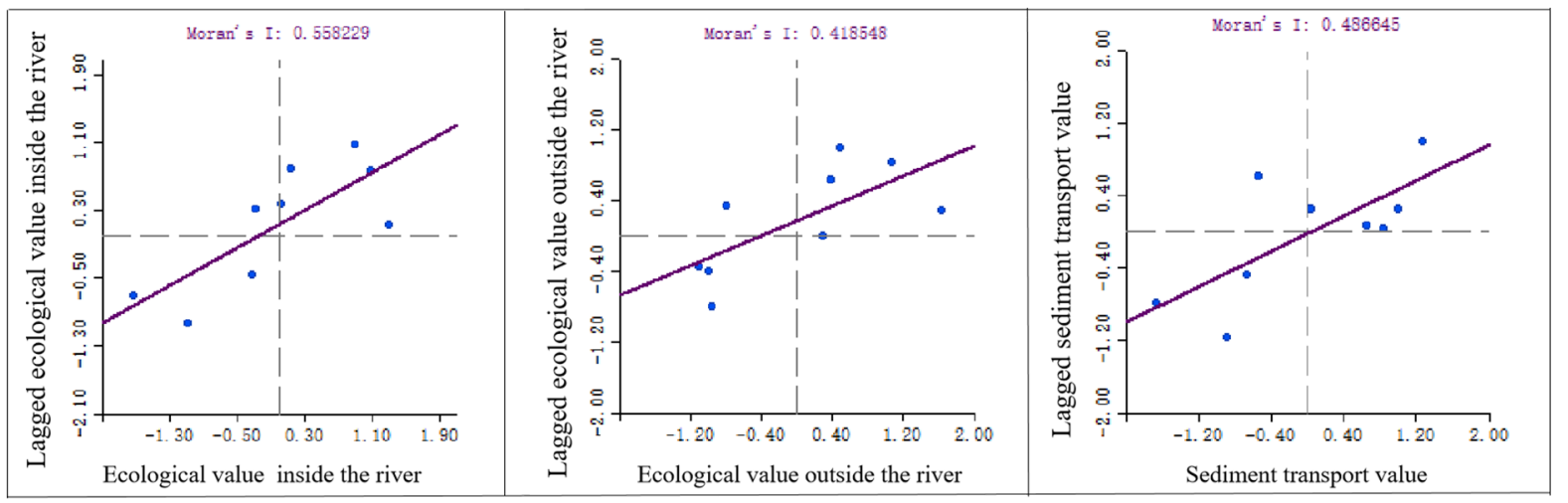

Figure 1 Moran scatter plot of value of EW in the Yellow River Basin

However, since the global Moran index can only reflect the overall spatial concentration of the water resources value of the agricultural system, in order to further investigate the clustering and heterogeneity of the value of EW in the local space, it is necessary to carry out the local spatial autocorrelation analysis of the water resources value of the Yellow River Basin. The results are shown Figure 2. The Yellow River basin is a life community, and the ecological environment quality of a region often affects the ecological environment quality of its surrounding areas. Both outside and inside the river course, the high concentration areas of ecological water value are in the middle and lower reaches, while the low concentration areas are in the lower reaches, which indicates that we should consolidate the ecological water value in the middle and lower reaches and enhance the water value in the upper reaches.

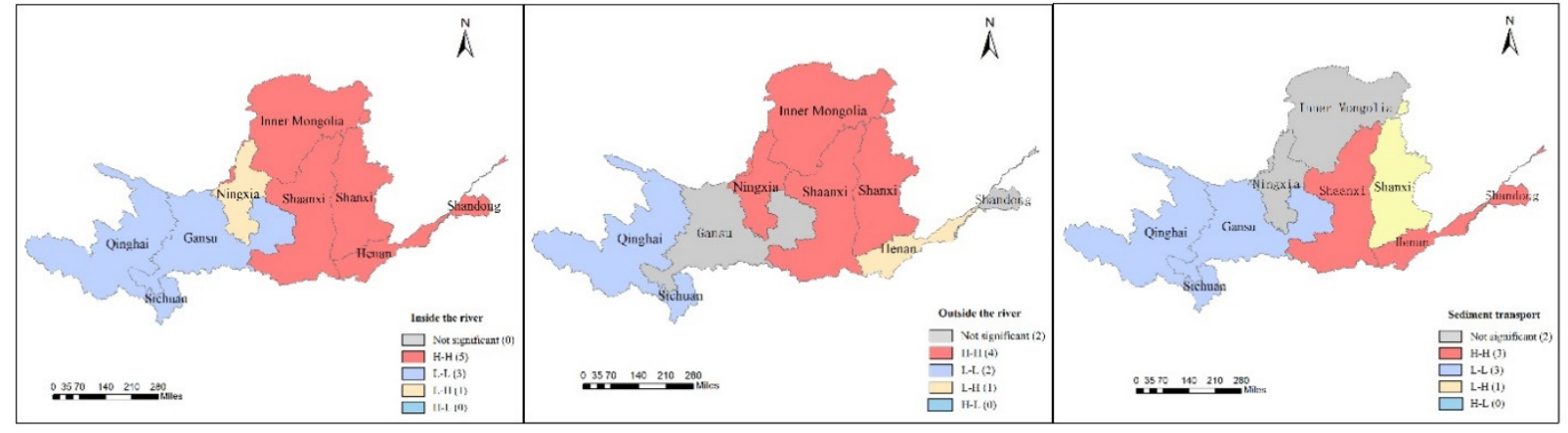

Figure 2 LISA concentration map of value of EW in the Yellow River Basin

\section{Conclusions}

The emergy analysis method is used to quantify the value of ecological water of the river basin, which solves the problem of low value caused by neglecting its natural attributes in most of the previous studies of water resources. In this paper, the spatial autocorrelation analysis method and spatial lag regression model are used to consider the influence of spatial geographical characteristics on the spatial distribution of water resources value from the perspective of the entire river basin, which breaks through the limitation that the previous research of water resources value is mostly concentrated in the provincial administrative region or the municipal administrative region.

\section{Reference}

1. Wang J Q, Ge J W, Cheng S P. Urban river ecological restoration based on improving the overall capacities of water-related ecosystem services[J]. Journal of Human Settlements in Wast China, 2018, 33(6): 5458.
2. Feld C K, Ferreira M T, Hering D, et al. Evaluating riparian solutions to multiple stressor problems in river ecosystems - A conceptual study[J]. Water Research, 2018, 139:381-394.

3. Wu, Z, Di, D, Wang, $\mathrm{H}^{*}, \mathrm{Wu}, \mathrm{M}, \mathrm{He}, \mathrm{C}$. Analysis and emergy assessment of the eco-environmental benefits of rivers. Ecological Indicators, 2019, 106: 105472.

4. Di, D, Wu, Z, Guo, X, Lv, C, Wang, H*. Value stream analysis and emergy evaluation of the water resource eco-economic system in the Yellow River Basin. Water, 2019,11(4): 710.

5. Peili D, Lijie Q, Yeqiao W, et al. Spatiotemporal Correlations between Water Footprint and Agricultural Inputs: A Case Study of Maize Production in Northeast China[J]. Water, 2015, 7(12):4026-4040. 